\title{
Analisa Parameter Hidrodinamika Remotely Operated Vehicle (ROV) Kelas Obervasi
}

\author{
Dhimas Satria*, Romi Wiryadinata, Ni Ketut Caturwati, Haryadi, Imron Rosyadi \\ Jurusan Teknik Mesin, Fakultas Teknik, Universitas Sultan Ageng Tirtayasa \\ Jl. Jenderal Sudirman Km 3, Kotabumi, Kec. Purwakarta, Kota Cilegon, Banten 42435 \\ *E-mail: dhimas@untirta.ac.id
}

\begin{abstract}
Remotely operated vehicle (ROV) of sub marine technology at sunda strait which has been developed has limitation in term of maneuver, which is only can move vertically with limited depth. This study aims to obtain the best hydrodynamic parameter, those are matrix inertia, matrix coriolis and hydrodynamic attenuation. The research method used was fixed mesh, in which it was assume that the fluid move with the velocity where ROV moved and ROV model was not moving (static). The representation of ROV movement by changing ROV slope toward fluid stream. The result of the research is hydrodynamic parameter, namely $M_{R B}$ (inertia Matrix of $R O V$ ), $C_{R B}$ (coefficient matrix for coriolis), $C_{A}$ (coefficient matrix for hydrodynamic with coriolis and centripetal) giving coefficient inertia for ROV body rotation frame to earth core. Meanwhile hydrodynamic parameter which is hydrodynamic attenuation describes hydrodynamic attenuation force and moment work at relative movement between the vehicle body and fluid.
\end{abstract}

Keywords: ROV, hydrodynamic, manuver

\section{Abstrak}

Remotely Operated Vehicle (ROV) teknologi observasi bawah laut di perairan selat Sunda yang telah dikembangkan memiliki keterbatasan dari segi manuver, yaitu hanya dapat bergerak vertical dengan kedalaman yang terbatas. Penelitian ini bertujuan untuk mendapatkan parameter hidrodinamika yang terbaik, yaitu matriks inersia, matrik coriolis, dan redaman hidrodinamika. Metode penelitian yang digunakan adalah metode fixed mesh, dimana diasumsikan fluida bergerak pada kecepatan dimana ROV bergerak dan model ROV diam (statik). Representasi gerak ROV dengan mengubah kemiringan ROV terhadap arah aliran fluida. Hasil dari penelitian adalah parameter hidrodinamika, yaitu $\mathbf{M}_{\mathbf{R B}}$ (matriks inersia benda tega ROV), $\mathbf{C}_{\mathbf{R B}}$ (Matriks koefisien untuk benda tega Coriolis), $\mathbf{M}_{\mathbf{A}}$ (inersia hidrodinamika), $\mathbf{C}_{\mathbf{A}}$ (matriks koefisien untuk hidrodinamika dengan Coriolis dan nilai sentripetal) memberikan koefisien inersia badan ROV kerangka rotasi terhadap titik pusat bumi. Sedangkan parameter hidrodinamika yaitu redaman hidrodiniamika menggambarkan gaya redaman hidrodinamika dan momen berkerja terhadap gerak relatif antara badan kendaraan dengan fluida.

Kata kunci: ROV, Hidrodinamika, Manuver

\section{Pendahuluan}

Alat observasi bawah air terdiri dari dua macam jenis, yaitu Remotely Operated Vehicle (ROV) dan Autonomous Unmanned Vehicle (AUV)[1, 2]. Kedua jenis alat observasi memiliki fungsi yang sama dengan sistem operasi yang berbeda. Telah banyak ROV yang dirancang sebagai alat observasi perairan $[3,4,5,6]$ dengan latar belakang pengembangan yang sama, juga sebagai alat observasi kebutuhan industri maupun penanggulangan bencana. Secara lebih khusus, permasalahan utama eksplorasi perairan Indonesia adalah teknologi observasi, dan telah dikembangkan oleh Wiryadinata suatu ROV teknologi observasi bawah laut di perairan selat Sunda [7]. ROV yang telah dikembangkan oleh Wiryadinata tersebut memiliki keterbatasan dari segi manuverbilitas, yaitu hanya bisa bergerak ke atas dan ke bawah dengan kedalaman tertentu, sehingga perlu dikembangkan lebih lanjut dari segi konsep desain dan analisa manuverbilitas. Satria, dkk. [8] telah mengembangkan konsep desain ROV dengan menggunakan metode concept screening dan concept scoring, dengan hasil konsep desain terpilih, yaitu small ROV dengan geometri streamlined/half-streamlined body yang memiliki konfigurasi pendorong rear-middle sebagai komponen gerak model hidrodinamika 3 DOF (surge, heave, dan yaw).

Penelitian ini bertujuan untuk menganalisa parameter hidrodinamik yang ke depan dapat dimanfaatkan untuk membentuk persamaan manuverbilitas, dimana parameter hidrodinamik tersebut adalah matriks inersia dan matrik Coriolis, yaitu $\mathbf{M}_{\mathbf{R B}}$ (matriks inersia benda tega ROV), $\mathbf{C}_{\mathbf{R B}}$ (Matriks koefisien untuk benda tega Coriolis), $\mathbf{M}_{\mathbf{A}}$ (inersia hidrodinamika), $\mathbf{C}_{\mathbf{A}}$ (matriks koefisien untuk hidrodinamik dengan Coriolis dan nilai sentripetal), serta redaman hidrodinamika. 


\section{Metode penelitian}

Telah ditentukan dalam spesifikasi produk yang merupakan kebutuhan pengguna, bahwa ROV berkerja dalam model 3 DOF. Sehingga, untuk mempermudah dalam solusi teori manuverbilitas, model rangka koordinat (coordinate frame) dari desain ROV terbentuk sesuai dengan tinjauan literatur [9] dimodelkan dalam Gambar 1 dengan referensi Gambar 2.

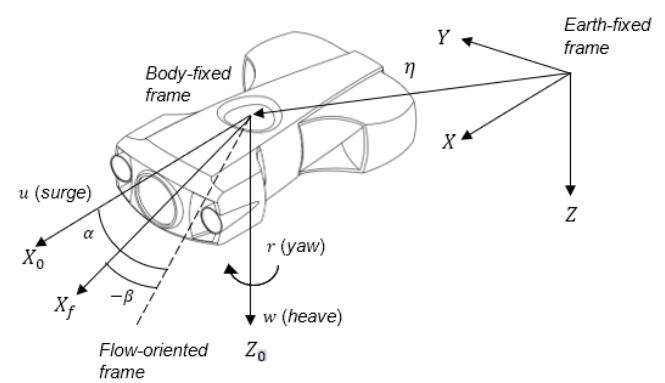

Gambar 1. Model koordinat ROV.

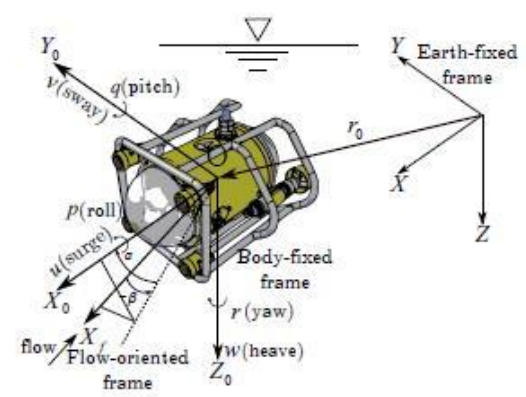

Gambar 2. Rangka koordinat dan kecepatan [9].

Gambar 1 tersusun dari tiga model (frame) koordinat yang bekerja pada badan ROV; flow oriented frame, Bodyfixed frame, dan earth-fixed frame. Ketiga model koordinat mempresentasikan referensi tidak berakselerasi (nonaccelerated). Model koordinat mudahkan dalam analisa model dan karakteristik hidrodinamika dengan prasyarat simulasi.

Penelitian ini menggunakan metode fixed mesh, dimana diasumsikan fluida bergerak pada kecepatan dimana ROV bergerak dan model ROV diam (statik). Representasi gerak ROV dengan mengubah kemiringan ROV terhadap arah aliran fluida. Tiga kondisi simulasi digunakan sebagai representasi gerak ROV, yaitu: Kasus 1, laju aliran fluida bergerak sejajar terhadap benda yang dengan simulasi gerak heave dari ROV, kasus 2, Laju aliran fluida dengan $\alpha=0$, $\beta$ bernilai 0 sampai 180 deg, dengan besar sudut perlangkah 30 deg menunjukkan simulasi ketika ROV bergerak untuk meningkatkan kedalaman ataupun sebaliknya, kasus 3, laju aliran fluida dengan $\beta=0$, $\alpha$ bernilai 0 sampai 80 deg, dengan besar sudut perlangkah 10 deg menunjukkan simulasi ketika ROV bergerak rotasi dengan besaran sudut langkah untuk gerak yaw.

Dalam penelitian yang dilakukan oleh Ramirez-Maciaz [9], analisa manuver dari kendaraan bawah laut dalam ruang tiga dimensi, rangka 3 koordinat perlu mendefinisikan: momen tetap terhadap poros bumi, yang dimana tetap terhadap titik pusat badan kendaraan dan bergerak bersamanya, dan rangka sejajar dengan arah datang aliran. Posisi dan orientasi dari kendaraan dideskripsikan relatif terhadap rangka tetap terhadap bumi (earth-fixed frame).

Persamaan kinetik benda tega ROV merupakan derivasi dengan asumsi linier. Untuk mendapatkan ketidaklinieran teori manuver, gaya sentripetal dan Coriolis di derivasikan dalam rangka Langarian. Matriks $\mathbf{C}_{\mathbf{A}}(\mathbf{V})$ dan $\mathbf{M}_{\mathbf{A}}$ dipertimbangkan.

Dimana $\mathbf{M}_{\mathbf{R B}}$ merupakan matriks inersia benda tega $\mathrm{ROV}$, dan $\mathbf{M}_{\mathbf{A}}$ merupakan inersia hidrodinamika. Kedua nilai matriks tersebut didefinisikan dalam:

$$
M_{R B}=\left[\begin{array}{cccccc}
m & 0 & 0 & 0 & 0 & 0 \\
0 & m & 0 & 0 & 0 & 0 \\
0 & 0 & m & 0 & 0 & 0 \\
0 & 0 & 0 & I_{x} & -I_{x y} & -I_{x z} \\
0 & 0 & 0 & -I_{y x} & I_{y} & -I_{y z} \\
0 & 0 & 0 & -I_{z x} & -I_{z y} & I_{z}
\end{array}\right]
$$




$$
M_{A}=-\left[\begin{array}{cccccc}
X_{\dot{u}} & X_{\dot{v}} & X_{\dot{w}} & X_{\dot{p}} & X_{\dot{q}} & X_{\dot{r}} \\
Y_{\dot{u}} & Y_{\dot{v}} & Y_{\dot{w}} & Y_{\dot{p}} & Y_{\dot{q}} & Y_{\dot{r}} \\
Z_{\dot{u}} & Z_{\dot{v}} & Z_{\dot{w}} & Z_{\dot{p}} & Z_{\dot{q}} & Z_{\dot{r}} \\
K_{\dot{u}} & K_{\dot{v}} & K_{\dot{w}} & K_{\dot{p}} & K_{\dot{q}} & K_{\dot{r}} \\
M_{\dot{u}} & M_{\dot{v}} & M_{\dot{w}} & M_{\dot{p}} & M_{\dot{q}} & M_{\dot{r}} \\
N_{\dot{u}} & N_{\dot{v}} & N_{\dot{w}} & N_{\dot{p}} & N_{\dot{q}} & N_{\dot{r}}
\end{array}\right]
$$

Dengan $\mathbf{m}$ adalah massa dari kendaraan, $\mathbf{I}=\left[\begin{array}{ccc}\mathbf{I}_{\mathbf{x}} & -\mathbf{I}_{\mathbf{x y}} & -\mathbf{I}_{\mathbf{x z}} \\ -\mathbf{I}_{\mathbf{y x}} & \mathbf{I}_{\mathbf{y}} & -\mathbf{I}_{\mathbf{y z}} \\ -\mathbf{I}_{\mathbf{z x}} & -\mathbf{I}_{\mathbf{z y}} & \mathbf{I}_{\mathbf{z}}\end{array}\right]$ adalah tensor inersia dari badan kendaraan, dan semua nilai dalam $\mathbf{M}_{\mathbf{A}}$ merupakan gaya hidrodinamik dengan koefisien mass force.

$$
\mathbf{C}(\mathbf{V})=\mathbf{C}_{\mathbf{R B}}(\mathbf{V})+\mathbf{C}_{\mathbf{A}}(\mathbf{V})
$$

Dimana $\mathbf{C}_{\mathbf{R B}}(\mathbf{V})$ adalah matriks koefisien untuk benda tega Coriolis dan nilai sentripetal, dan $\mathbf{C}_{\mathbf{A}}(\mathbf{V})$ adalah matriks koefisien untuk hidrodinamik dengan Coriolis dan nilai sentripetal, yang didefinisikan sebagai:

$$
\begin{aligned}
& \mathbf{C}_{\mathbf{R B}}=\left[\begin{array}{cccccc}
\mathbf{0} & \mathbf{0} & \mathbf{0} & \mathbf{0} & \mathbf{m w} & -\mathbf{m v} \\
\mathbf{0} & \mathbf{0} & \mathbf{0} & -\mathbf{m w} & \mathbf{0} & \mathbf{m u} \\
\mathbf{0} & \mathbf{0} & \mathbf{0} & \mathbf{m v} & -\mathbf{m u} & \mathbf{0} \\
\mathbf{0} & \mathbf{m w} & -\mathbf{m v} & \mathbf{0} & -\mathbf{I}_{\mathrm{yz}} \mathbf{q}-\mathbf{I}_{\mathrm{xz}} \mathbf{p}+\mathbf{I}_{\mathrm{z}} \mathbf{r} & \mathbf{I}_{\mathrm{yz}} \mathbf{q}+\mathbf{I}_{\mathrm{xz}} \mathbf{p}-\mathbf{I}_{\mathrm{z}} \mathbf{r} \\
-\mathbf{m w} & \mathbf{0} & \mathbf{m u} & \mathbf{I}_{\mathrm{yz}} \mathbf{q}+\mathbf{I}_{\mathrm{xz}} \mathbf{p}-\mathbf{I}_{\mathrm{z}} \mathbf{r} & \mathbf{0} & -\mathbf{I}_{\mathrm{xz}} \mathbf{r}-\mathbf{I}_{\mathrm{xy}} \mathbf{q}-\mathbf{I}_{\mathbf{x}} \mathbf{p} \\
\mathbf{m w} & -\mathbf{m w} & \mathbf{0} & -\mathbf{I}_{\mathrm{yz}} \mathbf{r}-\mathbf{I}_{\mathrm{xy}} \mathbf{p}+\mathbf{I}_{\mathrm{y}} \mathbf{q} & \mathbf{I}_{\mathrm{xz}} \mathbf{r}+\mathbf{I}_{\mathrm{xy}} \mathbf{q}-\mathbf{I}_{\mathrm{x}} \mathbf{p} & \mathbf{0}
\end{array}\right] \\
& \mathbf{C}_{\mathbf{A}}=\left[\begin{array}{cccccc}
\mathbf{0} & \mathbf{0} & \mathbf{0} & \mathbf{0} & -\mathbf{a}_{3} & \mathbf{a}_{2} \\
\mathbf{0} & \mathbf{0} & \mathbf{0} & \mathbf{a}_{3} & \mathbf{0} & -\mathbf{a}_{1} \\
\mathbf{0} & \mathbf{0} & \mathbf{0} & -\mathbf{a}_{2} & \mathbf{a}_{1} & \mathbf{0} \\
\mathbf{0} & -\mathbf{a}_{3} & \mathbf{a}_{2} & \mathbf{0} & -\mathbf{b}_{3} & \mathbf{b}_{2} \\
\mathbf{a}_{3} & \mathbf{0} & -\mathbf{a}_{1} & \mathbf{b}_{3} & \mathbf{0} & -\mathbf{b}_{1} \\
-\mathbf{a}_{2} & \mathbf{a}_{1} & \mathbf{0} & -\mathbf{b}_{2} & \mathbf{b}_{1} & \mathbf{0}
\end{array}\right]
\end{aligned}
$$

\section{Hasil dan Pembahasan}

Nilai inersa dari desain ROV terbentuk diperoleh dari model tiga dimensi (3D). Nilai inersia diperlukan untuk memperoleh matriks tensor inersia. Matriks tensor inersa membentuk matriks inersia benda tega ROV. Nilai sifat dimensional fisik badan kendaraan; meliputi masa kendaaraan, volume, luas permukaan, dan sebagai nya dikalkulasikan dalam peragkat lunak Solidworks [10]. Berikut adalah mass properties badan kendaraan yang disalin dari perangkat lunak Solidworks.

Dari sifat massa desain ROV yang diperoleh dari perangkat lunak CAD, substitusi inersia dari titik pusat massa (center of mass) dan inersia dari sistem koordinat (coordinat system) diperoleh tensor inersia dari badan ROV;

$$
I=\left[\begin{array}{ccc}
0.04 & 0 & 0 \\
0 & 0.18 & 0 \\
0 & 0 & 0.20
\end{array}\right]
$$

Dari matriks I menunjukan bahwa matriks dominan diagonal, sehingga dapat diperkirakan matriks I diagonal $\mathbf{I}=$ $\operatorname{diag}\{\mathbf{0 . 0 4}, \mathbf{0 . 1 8}, \mathbf{0 . 2 0}\}$. Elemen matriks I mendefinsikan parameter untuk $\mathbf{M}_{\mathbf{R B}}$ (matriks inersia benda tega ROV) dan $\mathbf{C}_{\mathbf{R B}}$ (Matriks koefisien untuk benda tega Coriolis).

$$
\begin{gathered}
\mathrm{M}_{\mathrm{RB}}=\operatorname{diag}\{8.5,8.5,8.5,0.04,0.18,0.20\} \\
\mathrm{C}_{\mathrm{RB}}(\mathrm{V})=\left[\begin{array}{cccccc}
0 & 0 & 0 & 0 & 8.5 w & -8.5 v \\
0 & 0 & 0 & -8.5 w & 0 & 8.5 u \\
0 & 0 & 0 & 8.5 w & 8.5 u & 0 \\
0 & 8.5 w & -8.5 v & 0 & 0.20 r & -0.18 q \\
-8.5 w & 0 & 8.5 u & -0.04 r & 0 & 0.04 p \\
8.5 v & -8.5 u & 0 & 0.18 q & -0.04 p & 0
\end{array}\right]
\end{gathered}
$$


Menggunakan asumsi geometri badan kendaraan silinder sebagai penyederhanaan, mengacu pada perkiraan matriks I diagonal dengan tiga bidang simetri dan benda tega dengan tiga bidang simetri, teori strip dengan persamaan berikut untuk semua koefisien gaya dan massa hidrodinamik dengan massa $\mathbf{m}=\mathbf{8}, \mathbf{5} \mathbf{~ k g}, \mathbf{r}=\mathbf{0}, \mathbf{1 2} \mathbf{~ m}, \mathbf{L}=\mathbf{0}, \mathbf{5 0 5} \mathbf{~ m}$, dan asumsi tenggelam pada kedalaman $\mathbf{h}=\mathbf{1 0 0} \mathbf{~ m}$ dengan densitas air laut $\boldsymbol{\rho}=\mathbf{1 0 2 0} \mathbf{~} \mathbf{~ g} / \mathbf{m}^{3}$. Maka;

$X_{u}=-0,85 ; Y_{v}=-23,3 ; Z_{x}=-23,3 ; M_{q}=-0,49 ; N_{r}=-0,4$

Sehingga, nilai $\mathbf{M}_{\mathbf{A}}$ (inersia hidrodinamika) dan $\mathbf{C}_{\mathbf{A}}$ (matriks koefisien untuk hidrodinamik dengan Coriolis dan nilai sentripetal) dengan paramater yang telah ditentukan didapatkan;

$$
M_{A}=\operatorname{diag}\{0,85 ; 23,3 ; 23,3 ; 0 ; 0,49 ; 0,49\}
$$

$$
\mathbf{C}_{\mathbf{A}}(\mathbf{V})=\left[\begin{array}{cccccc}
0 & 0 & 0 & 0 & 23,3 w & -23,3 v \\
0 & 0 & 0 & -23,3 w & 0 & 0,85 u \\
0 & 0 & 0 & 23,3 w & -0,85 u & 0 \\
0 & 23,3 w & -23,3 v & 0 & 0,49 r & -0,49 q \\
-23,3 w & 0 & 0,85 u & -0,49 r & 0 & 0 \\
23,3 v & -0,85 u & 0 & 0,49 q & 0 & 0
\end{array}\right]
$$

Keempat parameter $\left(\mathrm{M}_{\mathrm{RB}}, \mathrm{C}_{\mathrm{RB}}, \mathrm{M}_{\mathrm{A}}\right.$, dan $\left.\mathrm{C}_{\mathrm{A}}\right)$ memberikan koefisien inersia badan $\mathrm{ROV}$ kerangka rotasi terhadap titik pusat bumi. Koefisien inersia dari keempat parameter terdiri dari nilai kecepatan angular yang mendefinisikan kecepatan yang diperlukan oleh ROV untuk bergerak menurut sistem gerak yang diterapkan, yaitu sistem 3 DOF. Sehingga, nilai tersebut dapat digunakan untuk menentukan energi yang dibutuhkan oleh pendorong (thruster) dengan menyesuaikan koefisien inersia yang terbentuk.

Solusi koefiesien redaman hidrodinamik membutuhkan nilai gaya dan momen yang dialami pada badan kendaraan pada ketiga bidang dan koordinat. Untuk mempermudah dalam solusi koefisien redaman hidrodinamik, simulasi ketiga kasus teori manuverbilitas diterapkan sehingga memperoleh nilai gaya. Penerapan sudut dalam simulasi menggunakan nilai radian. Nilai radian diperoleh dengan mentranslasikan derajat kedalam nilai radian berdasarkan prinsip tangensial.

\begin{tabular}{|c|c|c|c|c|c|c|}
\hline \multirow{2}{*}{$\alpha$} & $\tau_{z}$ & $\tau_{y}$ & $\tau_{x}$ & $M_{z}$ & $M_{y}$ & $M_{x}$ \\
\hline & \multicolumn{3}{|c|}{ Unit $=N$} & \multicolumn{3}{|c|}{ Unit $=N m$} \\
\hline-180 & 21,679 & 77,348 & $-0,046$ & $-0,017$ & $-0,006$ & 15,856 \\
\hline-150 & 31,664 & $-63,451$ & $-0,533$ & 0,007 & 0,111 & $-36,605$ \\
\hline-120 & 17,500 & $-110,283$ & $-1,085$ & 0,011 & 0,288 & $-40,448$ \\
\hline-90 & 17,447 & $-99,635$ & 0,792 & $-0,003$ & 0,084 & $-30,548$ \\
\hline-60 & $-10,913$ & $-121,816$ & $-0,207$ & $-0,017$ & 0,119 & $-28,669$ \\
\hline-30 & $-44,467$ & $-63,761$ & $-0,247$ & 0,006 & 0,116 & $-16,882$ \\
\hline 0 & $-30,685$ & 83,030 & $-0,145$ & $-0,0004$ & 0,068 & 17,813 \\
\hline 30 & $-44,386$ & $-56,701$ & $-0,17$ & 0,001 & 0,057 & 51,788 \\
\hline 60 & $-10,619$ & $-119,230$ & $-2,825$ & $-0,087$ & 0,419 & 62,948 \\
\hline 90 & 15,655 & $-100,091$ & 1,094 & $-0,015$ & $-0,056$ & 68,265 \\
\hline 120 & 18,481 & $-110,771$ & 0,252 & $-0,027$ & 0,057 & 75,031 \\
\hline 150 & 29,651 & $-61,865$ & $-0,438$ & $-0,028$ & 0,158 & 70,395 \\
\hline 180 & 22,450 & 79,321 & $-0,145$ & $-0,001$ & 0,068 & 17,813 \\
\hline
\end{tabular}

Tabel 1. Data komputasi gaya dan momen terhadap angle of attack pada tiga sumbu koordinat

Tabel 2. Data komputasi variasi angle of sideslip pada tiga koordinat

\begin{tabular}{lcccccc}
\multirow{2}{*}{$\boldsymbol{\beta}$} & $\boldsymbol{\tau}_{\boldsymbol{\phi}}$ & $\boldsymbol{\tau}_{\boldsymbol{\theta}}$ & $\boldsymbol{\tau}_{\boldsymbol{\psi}}$ & $\boldsymbol{M}_{\boldsymbol{\phi}}$ & $\boldsymbol{M}_{\boldsymbol{\theta}}$ & $\boldsymbol{M}_{\boldsymbol{\psi}}$ \\
\cline { 2 - 7 } & & Unit $=N$ & & $-0,001$ & Unit $=N m$ & 0,068 \\
30 & $-30,685$ & 83,030 & $-0,145$ & 0,161 & 9,037 & 17,813 \\
60 & $-32,903$ & 85,544 & $-45,479$ & 0,145 & 18,401 & 18,451 \\
90 & $-13,903$ & 85,544 & $-188,406$ & 0,092 & 24,789 & 17,708 \\
120 & 4,922 & 82,473 & $-106,218$ & 0,16 & 31,053 & 17,134 \\
150 & 6,802 & 79,642 & $-105,604$ & 0,237 & 23,086 & 17,311 \\
180 & 20,122 & 82,425 & $-65,323$ & 0,005 & 0,067 & 16,731 \\
\hline
\end{tabular}


Model redaman hidrodiniamika menggambarkan gaya redaman hidrodinamik dan momen berkerja terhadap gerak relatif antara badan kendaraan dengan fluida. Badan kendaraan memiliki geometri simetri terhadap bidang $\mathbf{y}-\mathbf{z}$, sehingga gaya yang bekerja pada sisi kanan memiliki besar gaya yang sama terjadi pada sisi kiri terhadap fluida yang mengalir dari sumbu $\mathbf{- z}$. Sehingga gaya hidrodinamik tidak mempengaruhi pada arah sumbu $-\mathbf{x}$. Kondisi tidak ada nya pengaruh gaya hidrodinamik pada sumbu-x (dapat diasumsikan tidak ada karena bernilai kecil), sehingga $\boldsymbol{\tau}_{\mathbf{x}}$ tidak dipengaruhi oleh $\boldsymbol{\alpha}$, dan juga $\boldsymbol{\tau}_{\boldsymbol{\theta}}$ dan $\boldsymbol{\tau}_{\boldsymbol{\psi}}$ tidak dipengaruhi oleh $\boldsymbol{\alpha}$. Sistem model 3 DOF yang digunakan dan desain badan kendaraan simetri pada bidang $\mathbf{x}-\mathbf{z}$, mempengaruhi momen yang bekerja pada badan kendaraan. Keterbatasan kendaraan untuk berotasi pada sumbu tertentu dapat membentuk asumsi tidak ada pengaruh angle of sidesip $\boldsymbol{\beta}$ pada rotasi terhadap sumbu-z dan sumbu-X. Maka, $\boldsymbol{\tau}_{\mathbf{y}}, \boldsymbol{\tau}_{\boldsymbol{\phi}}$, dan $\boldsymbol{\tau}_{\boldsymbol{\psi}}$ tidak dipengaruhi oleh $\boldsymbol{\beta}$. Kendaraan bekerja pada model sistem 3 DOF; $\operatorname{surge}(\mathrm{u})$, heave (w), dan yaw (r). Maka dapat diasumsikan $\boldsymbol{\tau}_{\boldsymbol{\phi}}=\mathbf{0}$ dan $\boldsymbol{\tau}_{\boldsymbol{\Psi}}=\mathbf{0}$.

\section{Kesimpulan}

Parameter hidrodinamik, yaitu $\mathbf{M}_{\mathbf{R B}}$ (matriks inersia benda tega ROV), $\mathbf{C}_{\mathbf{R B}}$ (Matriks koefisien untuk benda tega Coriolis), $\mathbf{M}_{\mathbf{A}}$ (inersia hidrodinamika), $\mathbf{C}_{\mathbf{A}}$ (matriks koefisien untuk hidrodinamik dengan Coriolis dan nilai sentripetal) memberikan koefisien inersia badan ROV kerangka rotasi terhadap titik pusat bumi. Sedangkan parameter hidrodinamik yaitu redaman hidrodiniamika menggambarkan gaya redaman hidrodinamik dan momen berkerja terhadap gerak relatif antara badan kendaraan dengan fluida.

\section{Ucapan Terima Kasih}

Penulis mengucapkan terimakasih kepada DRPM Kemristekdikti, LPPM Untirta, dan Fakultas Teknik Untirta yang telah mendukung terkait dana untuk terselanggaranya penelitian ini.

\section{Daftar Pustaka}

[1] R. D. Christ, 2007, "The ROV Manual", Oxford: Elsevier.

[2] F. Aguirre, 2017, "State of the Art of Parameters for Mechanical Design of an Autonomous Underwater Vehicle", International Journal of Oceans and Oceanography, vol. 11, pp. 89-113, 2017.

[3] I. Rizki, 2008, "Pengembangan Prototipe Remotely Operated Vehicle (ROV): Aspek Mekanis", Skripsi S1 Ilmu dan Teknologi Kelautan, Institut Pertanian Bogor.

[4] M. Jumarang, 2013, "Transpor Volume Massa Air Di Selat Sunda Akibat Interaksi", Prosiding Semirata FMIPA Universitas Lampung.

[5] Z. Husin, 2014, "Studi Awal Perancangan Prototipe Remotely Operated Vehicle (ROV)", Mikrotiga, pp. 31-36.

[6] S. Manullang, 2016, "Analisis Desain Awal Rancang Bangun Remotely Operated Vehicle (ROV)", Seminar Hasil Penelitian Semester Genap 2015/2016 UNSADA.

[7] R. Wiryadinata, A. S. Nurliany, I. Muttakin, T. Firmansyah, 2017, "Design of a Low Cost Remotely Operated Vehicle with 3 DoF Navigation", Bulletin of Electrical Engineering and Informatics, vol. 6, no. 1, pp. 13-23.

[8] D. Satria, D. Pujangga, A. Lanank, and N. K. Caturwati, 2018, "Body Design Concept of Remotely Operated Vehicle ( ROV ) of Observation Class with the Method of Concept Screening and Concept Scoring", in The 1st International Conference on Industrial, Electrical and Electronics (ICIEE 2018), vol. 2009.

[9] J. Ramirez-Macias, 2016, "Hydrodynamic Modelling for the Remotely Operated Vehicle Visor3 Using CFD", IFAC Paper Online, pp. 187-192.

[10] H. Zhang, 2010, "Using CFD Software to Calculate Hydrodynamic Coefficients", Marine Science Applied, vol. 9, pp. 149-155. 